\title{
FORMULATION DEVELOPMENT, CHARACTERIZATION, AND IN VITRO-IN VIVO STUDY OF ANTIHYPERLIPIDEMIC DRUG ROSUVASTATIN CALCIUM - SOLID LIPID NANOPARTICLES
}

\author{
HARJEET SINGH ${ }^{1 *}$, RAM DAYAL GUPTA ${ }^{2}$ AND GIRENDRA GAUTAM ${ }^{3}$
}

${ }^{1}$ Department of Pharmacy, Research Scholar, Bhagwant University, Ajmer - 305 004, Rajasthan, India. ${ }^{2}$ Department of Pharmaceutics, H.R. Institute of Pharmacy, Morta, Ghaziabad - 201 003, Uttar Pradesh, India. ${ }^{3}$ Department of Pharmacy, Bhagwant University, Ajmer - 305004 , Rajasthan, India. Email: h_singh1gill@yahoo.co.in

Received: 21 March 2018, Revised and Accepted: 27 April 2018

ABSTRACT

Objective: The aim of this study was to formulate and optimize solid lipid nanoparticles (SLNs) for the enhancement of solubility and bioavailability of the poorly aqueous soluble drug rosuvastatin calcium.

Methods: SLNs were prepared by slight modification of solvent emulsification-diffusion technique and analyzed for particle size, zeta potential, drug entrapment efficiency, in vitro drug release, stability, and pharmacokinetic studies. Rosuvastatin calcium SLNs were formulated using stearic acid as main lipid, poloxamer 407 as surfactant, and Tween 80 as cosurfactant.

Results: All parameters were found to be in an acceptable range. Optimized formulation OR2 SLNs have shown mean particle size $115.49 \pm 2.97$ nm with polydispersity index value of 0.456 , zeta potential - $18.40 \mathrm{mV}, 60.34 \%$ drug loading, and $97.16 \%$ drug entrapment efficiency. In vitro drug release was found to be $88.70 \pm 3.59 \%$ after $12 \mathrm{~h}$ with sustained release and was fitted with Higuchi model with a very high correlation coefficient $\left(\mathrm{R}^{2}=0.9905\right)$. Transmission electron microscopy confirms that the SLNs of selected optimized formulation are circular in shape. Differential scanning calorimetry and X-ray diffraction confirm the formation of amorphous product. ${ }^{1} \mathrm{H}$ nuclear magnetic resonance studies confirm the intermolecular hydrogen bonding between drug and lipid. Pharmacokinetic studies showed an optimized formulation OR2 SLNs enhanced bioavailability with 4.44-fold as compare to plain drug suspension. Optimized formulation OR2 SLNs have shown good stability at $25 \pm 2^{\circ} \mathrm{C}$ and $60 \pm 5^{\circ} \mathrm{C}$ relative humidity for 180 days.

Conclusion: Thus, the current study can be useful for the successful development of optimized SLNs and able to enhance the bioavailability of poorly soluble drug rosuvastatin calcium.

Key words: Rosuvastatin, Stearic acid, Solid lipid nanoparticles, Pharmacokinetic study.

(c) 2018 The Authors. Published by Innovare Academic Sciences Pvt Ltd. This is an open access article under the CC BY license (http://creativecommons. org/licenses/by/4. 0/) DOI: http://dx.doi.org/10.22159/ajpcr.2018.v11i7.26177

\section{INTRODUCTION}

Oral route of medication is the most common and preferred route among all methods of administering medication. Solid dosage forms have gained popularity because of their ease of administration, accurate dosages, self-medication, pain avoidance, and, most importantly, patient compliance, but the oral route depends on the bioavailability of effective pharmaceutical ingredients. The speed and degree of medication reach the blood circulation, and thus, metabolism of the drug in the system [1]. Solubility of non-dissolving drugs in improving their pharmacological and biological level remains one of the major technological problems. Water solubility is one of the major determinants of the development of new chemical entities as effective drugs. Nearly $40 \%$ of all new drug candidates are classified as poorly soluble, preventing the development of pharmaceuticals [2]. Lipid-based drug delivery systems are introduced to overcome the limitations associated with traditional formulations. These systems offer large variety of options such as solutions, suspensions, emulsions, microemulsions, self-emulsifying drug delivery systems (SEDDSs), dry emulsions, and solid lipid nanoparticles (SLNs) [3]. SLNs are a newer approach gaining popularity; nowadays, as it is the most desirable and easy to manufacture formulation for the enhancement of solubility of poorly water-soluble drugs. The formulation of nanoparticles is giving higher efficacy and lesser toxicity for the cure of numerous diseases [4]. SLNs were introduced in 1991 and provide delivery systems for attractive, less toxic drugs compared to polymer systems that combine the advantages of polymeric nanoparticles, lipid and liposomal emulsions [5]. SLNs are attractive submicron colloidal carriers (50-1000 nm) used for both water-loving and fat-loving drugs. Drugs are entrapped in the heart of the biocompatible lipid and the surface agent in the outer layer. SLN can be used to improve biological availability and achieve continuous release of the drug. They provide benefits such as the lack of acute and chronic toxicity of carrier, good tolerability, and biodegradability, as well as widespread expansion in production. In addition, the method can be modified to achieve the release of the desired drug and the drug can be protected against chemical/enzymatic degradation [6]. Hence, SLNs are, therefore, a better alternative to polymeric nanoparticles, lipoproteins, microemulsions, nanoparticles, and self-emulsifying delivery systems. Rosuvastatin calcium is a fully synthetic 3-hydroxy3-methylglutaryl coenzyme A (HMG-CoA) reductase inhibitor and has dose-linear pharmacokinetics. Rosuvastatin calcium is BCS ClassII drug (low solubility and high permeability). Rosuvastatin is used as an adjunct to dietary therapy to treat primary hyperlipidemia, mixed dyslipidemia, and hypertriglyceridemia. The absolute oral bioavailability of rosuvastatin calcium is approximately $20 \%$ and a halflife of $19 \mathrm{~h}$ [7]. Rosuvastatin is subjected to metabolism for the first passage and a low rate of rosuvastatin $(10 \%)$ is recovered as metabolites, mainly N-desmethyl rosuvastatin, which have about one-sixth to half the inhibitory activity of rosuvastatin $\mathrm{HMG}$-CoA reductase. Cytochrome P450 (CYP) 2C9 is the primary enzyme responsible for the metabolism of rosuvastatin, with minimal effect of CYP2C19 [8]. The solubility of the drug can be improved by reducing the particle size of the drug or by increasing the drug's moisturizing properties of drugs through the use of surfactant. Thus, the objective of this study is prepared and optimize SEDDS (SLNs) to improve the solubility, and hence the bioavailability of rosuvastatin calcium, a poorly water-soluble drug. 


\section{MATERIALS AND METHODS}

\section{Materials}

Rosuvastatin calcium was provided as a gift sample by Sun Pharmaceuticals Ltd. (Gurgaon, Haryana, India). Stearic acid (Acros Organics, U.S.A), Poloxamer 407 (BASF, USA), palmitic acid, and Tween 80 LR were supplied by CDH Ltd., New Delhi, India. Precirol ATO 5, Glyceryl monostearate, and Compritol ATO 888 were obtained as a gift from Asoj Soft Caps, Baroda, India. Double distilled water was used throughout the studies. All other solvents and chemicals were of analytical grade.

\section{Methods}

\section{Excipients selection}

Lipid and surfactants are the main components of SLNs. The most important factors determining the loading capacity of the drug in the lipid are the solubility of the drug in the dissolved lipid. However, studies of equilibrium solubility cannot be done in this case. Therefore, we used a slightly modified method to determine the solid lipid that had the best dissolving or melting potential of the drug [9]. Stearic acid, Compritol ATO, 888, Precirol ATO 5, Glyceryl monostearate, and palmitic acid were tested for their ability to solubilize rosuvastatin. At first, solid lipids are heated above their melting points. Excess rosuvastatin $(20 \mathrm{mg})$ was placed in the threaded tubes. These lipid melts were gradually added in doses to the drug-containing tubes with continuous agitation using a vortex mixer and maintaining the same temperature (above the lipid melting point). The last point was the formation of a faint pale yellow solution of molten fat. The amount of molten fat required to dissolve visual rosuvastatin has been observed. The experiment was conducted in triplicate. The compatibility between the lipids and drug was identified by Fourier transform-infrared spectrophotometer (FTIR). Infrared spectra were obtained using a Shimadzu FTIR-8400 spectrometer (Shimadzu, Japan). The sample of pure drug, lipid, and physical mixture (PM) was previously ground and mixed thoroughly with $\mathrm{KBr}$, an infrared transparent matrix. The $\mathrm{KBr}$ disks were prepared by compressing the powder. The four scans were executed at a resolution of $1 / \mathrm{cm}$ (from 400 to $4000 / \mathrm{cm}$ ) [10].

\section{Preparation of rosuvastatin-loaded SLNs}

In an introductory laboratory study, several factors such as lipid concentration (stearic acid, 20-100 mg), surfactant concentration (Poloxamer 407 and Tween 80 in 1:1 [\% w/v], 0.5-2.5\%), stirring speed (2000-4000 rpm), drug amount (rosuvastatin, 10-50 mg) chloroform: ethanol ratio $(1: 1,2.5 \% \mathrm{v} / \mathrm{v})$ as the solvent of drug and lipids and sonication time $5 \mathrm{~min}$ were fixed and their effect on particle size, entrapment efficiency was determined. These factors were optimized in the study [11]. In the current study, all of the experiments were performed in triplicate and the averages were considered as the response. Table 1 summarizes the composition of various batches. Rosuvastatin calcium-loaded SLNs were prepared by slight modification of the previously reported solvent emulsificationdiffusion technique [12-15].

Accurately weighed amount of lipid (20-100 mg) was dissolved in a $2.5 \mathrm{~mL}(2.5 \% \mathrm{v} / \mathrm{v})$ mixture of methanol and chloroform $(1: 1)$ as the internal oil phase. Drug (10-50 mg, ratio of drug to lipid 1:2) was dispersed in the above solution. This organic phase was added drop by drop into a homogenizer tube containing $22.5 \mathrm{~mL}$ of an aqueous solution of surfactant and cosurfactant Poloxamer 407 and Tween
80 in $1: 1 \% \mathrm{w} / \mathrm{v}(0.5-2.5 \% \mathrm{w} / \mathrm{v})$ as external aqueous phase and homogenized for $30 \mathrm{~min}$ at stirring speed (2000-4000 rpm) (Remi Instruments Pvt., Ltd., India) to form a primary emulsion (o/w). The above primary emulsion was then poured into $75 \mathrm{~mL}$ of ice-cold water $\left(2-3^{\circ} \mathrm{C}\right)$ containing surfactant $(0.5-2.5 \% \mathrm{w} / \mathrm{v})$ and stirred to extract the organic solvent into the continuous phase and for proper solidification of SLNs. The stirring was continued for $2 \mathrm{~h}$ at (2000$4000 \mathrm{rpm}$ ) to disperse the SLNs. The SLN dispersion was sonicated for 5 min (1 cycle, 100\% amplitude, Bandelin Sonopuls, Germany) to produce SLN dispersions of uniform size. The dispersion was then centrifuged at 18,000 rpm for 20 min (Remi Instruments Pvt., Ltd., India) to separate the solid lipid material containing the drug and washed with deionized water time to ensure the complete removal of organic solvent. This was then redispersed in $(0.5-2.5 \% \mathrm{w} / \mathrm{v})$ aqueous surfactant mixture of surfactant and cosurfactant Poloxamer 407 and Tween 80 in 1:1\% w/v and sonicated for $5 \mathrm{~min}$ to obtain the SLNs. The SLN dispersions were lyophilized in the presence of $5 \%(\mathrm{w} / \mathrm{v})$ mannitol as cryoprotectant.

\section{Particle size, polydispersity index (PDI), and zeta potential}

Average particle size, the PDI (to determine the width of particle size distribution), the zeta potential (to characterize the particle's surface charge and the physical stability of colloidal pigments) from the rosuvastatin calcium-induced SLN dispersion measured by photon correlation spectroscopy (PCS) using the Malvern Instruments, HAS 3000: Malvern, United Kingdom. The analysis was performed at $25^{\circ} \mathrm{C}$ with a detection angle of $90^{\circ}$. The dilute nanoparticle dispersion was poured into the disposable sizing cuvette and then placed in the cuvette holder of instrument and analyzed. Air bubbles, if any, are removed from the capillaries before measurement [16].

\section{Drug loading and drug entrapment efficiency}

A fixed quantity of SLNs dispersions $(10 \mathrm{~mL})$ was ultracentrifuged for $1 \mathrm{~h}$ at $20^{\circ} \mathrm{C}$ and $18,000 \mathrm{rpm}$ (REMI International, Mumbai, India), and the amount of drug presents in the clear supernatant after centrifugation was determined $(\mathrm{w})$ by UV spectrophotometer (Shimadzu ultraviolet [UV]-1700, Kyoto, Japan) at $243 \mathrm{~nm}$ [17]. The drug loading (\%) and drug entrapment efficiency (\%) were calculated by following equations:

Drug loading $(\%)=(W t-W s) /\left(W t-W s+W_{L}\right) \times 100$

Drug entrapment efficiency $(\%)=(\mathrm{Wt}-\mathrm{Ws}) / \mathrm{Wt} \times 100$

Where, Ws is the weight of drug in the supernatant after centrifugation, $\mathrm{Wt}$ is the total weight of drug used, and $\mathrm{W}_{\mathrm{L}}$ is the weight of the lipid used in preparing the SLNs.

\section{In vitro drug release and release kinetics study}

A ROS-SLN release study was performed using a dialysis membrane (HiMedia, 12,000-14,000 D molecular weight of the cut). An appropriate amount of ROS-SLN was taken containing a drug equivalent to $5 \mathrm{mg}$ in the dialysis bag and sealed at both ends. A dialysis bag is placed in the receptor chamber containing $100 \mathrm{ml}$ of phosphate buffer $\mathrm{pH} 6.8$. The temperature was maintained at $37^{\circ} \mathrm{C} \pm 2^{\circ} \mathrm{C}$ and was magnetically stirred at $100 \mathrm{rpm}$. Samples were taken from the receptor chamber at regular intervals of $60 \mathrm{~min}-12 \mathrm{~h}$ from the receiving chamber (flask) and replaced with an equal amount of the fresh phosphate buffer solution to maintain the sink condition. Sampling was determined by a UV spectrophotometer (Shimadzu UV-1700, Kyoto, Japan) at $243 \mathrm{~nm}$. All

Table 1: Composition of various batches of rosuvastatin-loaded SLNs

\begin{tabular}{llllll}
\hline S. No. & Formulation code & Variables & & & \\
\cline { 3 - 6 } & & Lipid (mg) & Surfactant $\mathbf{( \% w} / \mathbf{v})$ & Stirring speed (rpm) & Drug (mg) \\
\hline 1. & OR1 & 80 & 2 & 3500 & 40 \\
2. & OR2 & 80 & 2.25 & 4000 & 40 \\
3. & OR3 & 90 & 2.5 & 3500 & 40 \\
4. & OR4 & 90 & 4000 & 40 \\
\hline
\end{tabular}

SLNs: Solid lipid nanoparticles 
experiments were conducted in 3 times. The graph was drawn between the percentage cumulative of drug release versus time (hours) $[18,19]$

The results obtained from the in vitro release studies in nanoparticles have been fit into many kinetic equations such as zero order (percentage cumulative release vs. time), the first order (log percentage remaining vs. time), Higuchi (cumulative release of drugs vs. square), and Korsmeyer-Peppas (log cumulative percentage drug release vs. log time). The correlation coefficients $\left(\mathrm{R}^{2}\right)$ and $\mathrm{K}$ were determined for the linear curve obtained by regression analysis of the plots. Initial equations for various models are given below:

Zero-order model: $\mathrm{X}=\mathrm{Kt}$

First-order model: $\log \mathrm{X}=\mathrm{Kt} / 2.303$

Higuchi release model: $\mathrm{X}=\mathrm{K}(\mathrm{t})^{1 / 2}$

Korsmeyer-Peppas equation: $\log \mathrm{X}=\log \mathrm{K}+\mathrm{nlog} \mathrm{t}$

Where, $\mathrm{X}$ is the amount of drug released, $\mathrm{K}$ is the release rate constant, and $t$ is time. To construct the plot for zero-order and the Higuchi model, percent cumulative drug release determined, for the first model, log percent drug remaining was determined, and for Korsmeyer-Peppas equation, log cumulative percent drug release was determined [20-23].

Surface morphology by transmission electron microscopy (TEM) TEM was used for microscopic evaluation of the optimized formulation ROS-SLNs. Surface morphology was determined from SLNs designed using TEM (Philips CM 10, Netherlands). To evaluate, one drop (about $10 \mu \mathrm{l}$ ) of SLN dispersions was diluted with distilled water (1:100), filtered $(0.22 \mu \mathrm{m})$, and applied to a carbon-coated grid with dye solution phosphotungstic acid 2\% (PTA) for $30 \mathrm{~s}$. The dried coated mesh was taken onto a slide and covered with a coverslip and was placed on 400 mesh copper grids with films to monitor the surface morphology [24].

\section{X-ray diffraction (XRD) analysis}

Diffraction patterns of pure drug, lipid, and optimized ROS-SLNs were improved with the D-8 advance SRD-Bruker (Germany). A $40 \mathrm{kV}$ and $30 \mathrm{~mA}$ power were used for the generator, with copper being used as anode in the tube. The solids of the $\mathrm{Cu}-\mathrm{K} \alpha$ radiation $(\alpha 1=1.54060 \AA$ and $\alpha 2=1.54439 \AA$ with $\alpha 1 / \alpha 2$ of 0.5 ) were exposed in the range of $2 \theta$ angles from $10^{\circ} \mathrm{C}$ to $30^{\circ} \mathrm{C}$, at the angular velocity of $1^{\circ}(2 \theta) \mathrm{min}$. Percentage crystallinity index was calculated by following equation No. 7 [25].

Where, \% crystallinity index $=\mathrm{I}_{020}-\mathrm{I} \mathrm{am} / \mathrm{I}_{020} \times 100$

$\mathrm{I}_{020}$ is intensity at $20^{\circ}$

I am is lowest $2 \theta$ near $8^{\circ}$.

\section{Differential scanning calorimetry (DSC)}

The improved thermal images of pure drug, lipid, PM, and optimized formulation ROS-SLNs were recorded in the Perkin-Elmer (Pyris Diamond) model differential scanning calorimeter. About $10 \mathrm{mg}$ samples were sealed in aluminum trays and an empty aluminum tray used as reference. The experiment was conducted under a stream of nitrogen $(20 \mathrm{ml} / \mathrm{min})$ at a rate of $10^{\circ} \mathrm{C} / \mathrm{min}$ from 30 to $300^{\circ} \mathrm{C}$ [26].

\section{${ }^{1} \mathrm{H}$ nuclear magnetic resonance (NMR) spectroscopy}

To determine the nature of the proton or the proton group in the pure drug, lipids, and optimized formulation ROS-SLNs, the ${ }^{1}$ HNMR spectrum in dimethyl sulfoxide was recorded in the Bruker Advance II FT-NMR (DRX-400, JAPAN) $300 \mathrm{MHz}$ spectroscopy, using tetramethylsilane as an internal standard, chemical shift $(\delta)$ was recorded in ppm [27].

\section{Pharmacokinetic studies}

The pharmacokinetic study of optimized ROS-SLNs was determined in comparison with pure drug in male albino Wistar rats (adult/weighing $180-250 \mathrm{gm})$. The animals were procured from animal house Devsthali
Vidyapeeth College of Pharmacy, Kichha Road, Lalpur, Rudrapur, U.S. Nagar, UK-263148, India. General and environmental conditions were strictly monitored. Animal handling routines were performed according to good laboratory practice. The temperature of $22 \pm 3^{\circ} \mathrm{C}$ and relative humidity (RH) $30-70 \%$ was maintained. Animals had free access to food and water was made available ad libitum. A study protocol for animal studies was approved by the Institutional Animal Ethics Committee of Devsthali Vidyapeeth College of Pharmacy, Kichha Road, Lalpur, Rudrapur, U.S. Nagar, UK-263148, India (Registration No:1452/PO/Re/S/11/CPCSEA).

The male Wistar rats were divided into three groups - control, reference, and test each consisting of six animals. In Group I - control (distilled water $10 \mathrm{~mL} / \mathrm{kg}$ ); Group II - (reference) plain drug suspension in $700 \mathrm{ng} / \mathrm{kg}$, and Group III - (test) optimized ROS-SLNs (700 ng/kg) were taken and in Group II and III additionally CMC-Na $(0.5 \% \mathrm{w} / \mathrm{v})$ as a suspending agent was received, respectively. The animals were kept on fasting for 10-12 h before the study. Under light ether anesthesia, blood samples (about $0.3 \mathrm{~mL}$ ) were withdrawn into heparinized tubes $0,0.5,1,2,4,8$, and 24 h through retro-orbital puncture or from tail vein route. Plasma was separated by centrifugation at $3000 \mathrm{rpm}$, $15 \mathrm{~min}$ at $4^{\circ} \mathrm{C}$. About $100 \mu \mathrm{L}$ of plasma sample along with $100 \mathrm{ng} / \mathrm{mL}$ of simvastatin, as internal standard, was mixed with $1 \mathrm{~mL}$ ethyl acetate as extracting solvent (liquid-liquid extraction technique). The samples were vortexed for $5 \mathrm{~min}$ and then centrifuged at $4000 \mathrm{rpm}$ for $10 \mathrm{~min}$. The remaining supernatant $(900 \mu \mathrm{L})$ was evaporated under a gentle stream of nitrogen at $40^{\circ} \mathrm{C}$ using nitrogen gas at room temperature. The dried samples were reconstituted with $0.3 \mathrm{~mL}$ of mobile phase and evaluated by high-performance liquid chromatography for the presence of ROS. Plasma drug concentration-time profile of samples for each group was evaluated with pharmacokinetic software (PK functions for Microsoft Excel, Pharsight Corporation, Mountain View, CA, USA). Various pharmacokinetic parameters such as $\mathrm{C}_{\max }, \mathrm{T}_{\max }, \mathrm{AUC}_{0-\mathrm{t}}, \mathrm{K}_{\mathrm{E}}, \mathrm{T}_{1 / 2}$, MRT, and $\mathrm{AUMC}_{0-\mathrm{t}}$ were calculated $[28,29]$.

\section{Stability studies}

A stable product is one, which retains its chemical safety and energy mark (chemical properties) within specified limits, retains its appearance, uniformity, palatability, its physical viability, solubility, resists microbial growth (microbiological stability), and the therapeutic effect remains unchanged without significant increase in toxicity over the course of life. ICH guidelines determine storage conditions to evaluate the stability of pharmaceutical products. The stability study was conducted to determine the effect of formulation additives on the stability of the drug and also to determine the physical stability of the prepared preparation under storage temperature and RH. The optimized formulation ROS-SLNs were analyzed for stability studies and these studies were performed in triplicate. The storage conditions used for stability testing were $4 \pm 2^{\circ} \mathrm{C}$ (refrigerator), $25 \pm 2^{\circ} \mathrm{C} / 60 \pm 5^{\circ} \mathrm{C} \mathrm{RH}$, and $40 \pm 2^{\circ} \mathrm{C} / 75 \pm 5^{\circ} \mathrm{C} \mathrm{RH}$, in stability chamber (Hicon Instruments Ltd., New Delhi). The samples were withdrawn after the period of $0,1,3$, and 6 months, and the effect on particle size, PDI, zeta potential, entrapment efficiency, and loading capacity was evaluated $[24,30]$.

\section{Statistical analysis}

All the data are reported as mean \pm standard deviation (SD). Differences between the groups were tested using t-test. $\mathrm{p}<0.05$ was considered statistically significant.

\section{RESULTS AND DISCUSSION}

\section{Excipients selection}

Excipients play a key role in formulation development of dosage forms. It should be pharmaceutically inert, acceptable, non-sensitive, and nonirritating in nature. They must be regarded as safe. For the preparation of SLNs, selection of a suitable lipid and surfactant is important. The drug solubility in lipid is an important determinant of its encapsulation efficiency. High encapsulation efficiency is due to high lipid solubility of drug and vice versa [31]. 
Measurement of the solubility of drug in the lipids was determined and the data are presented in Table 2. Solubility studies result shows that the drug was maximum soluble in stearic acid as compare to Compritol ATO 888, Precirol ATO \%, Glyceryl monostearate, and palmitic acid. The solubilizing efficiency of drug in lipid, already reported biocompatibility and its acceptability for SLNs approve its selection for the current research work [32].

The FTIR spectra scanning range was $400-4000 / \mathrm{cm}$ for ROS, stearic acid and PM are shown in Fig. 1. Results of FTIR spectra show the characteristic peaks at $3452.12 / \mathrm{cm}(\mathrm{O}-\mathrm{H}$ stretch vibration), $2850.19 / \mathrm{cm}$ (C-H stretch vibration), 1724.12/cm (stretch vibration $\mathrm{C}=0$ carbonyl functional group), 2968.52/cm ( $-\mathrm{N}-\mathrm{H}$ stretch vibration), $1547.88 / \mathrm{cm}$ ( $-\mathrm{C}=\mathrm{C}$ stretch vibration), $2850.19 / \mathrm{cm}$ (=C-H stretch vibration), $1509.81 / \mathrm{cm}$ (-N-H bending), 1381.13/cm (-CH3 symmetric), and $1335.60 / \mathrm{cm} \mathrm{(-S=0} \mathrm{symmetric).} \mathrm{The} \mathrm{FTIR} \mathrm{spectra} \mathrm{of} \mathrm{PM} \mathrm{seemed}$ to be only a summation of drug and lipid. This result suggested that there were no interactions between drug and lipid in PM, and also, rosuvastatin maintained its crystallinity as observed in thermal analysis [33].

On the basis of drug-lipid solubility and drug-lipid compatibility study, stearic acid was selected as the lipid. The surfactant for preparing SLNs was selected on the basis of hydrophilic-lipophilic balance (HLB) value that can emulsify lipid and form the stable microemulsion in an acceptable concentration. Poloxamer 407 with HLB of 18 was selected as the surfactant and Tween 80 with HLB of 15 was selected as the cosurfactant.

\section{Particle size, PDI, and zeta potential}

The surfactant concentration was optimizing as in respect to get a smaller size of SLNs with greater entrapment efficiency. The optimized surfactant concentration was $2.25 \% \mathrm{w} / \mathrm{v}$. The average particle size, PDI, and zeta potential of optimized formulation (OR2) were found to $115.49 \mathrm{~nm}, 0.456$, and $-18.40 \mathrm{mV}$, respectively. The mean particle size of different batches of SLNs ranges from $115.49 \pm 2.97$ to $141.65 \pm 3.89$. The particle size of optimized formulation (OR2) was appreciably lower $115.49 \pm 2.97 \mathrm{~nm}$ compared to other batches. This is due to increase in concentration of surfactant in OR2 formulation in comparison of other batches. Furthermore, by the addition of surfactant to SLNs that cause the interfacial film to condense and stabilize [34]. The particles of all batches are in the nano range which is proved from the PDI values. PDI is essentially the ratio of SD to mean particle size. The value of PDI is shown in Table 3 and was acceptable for all batches. Percent entrapment efficiency and drug loading of all batches are shown in Table 3 and value of the optimized batch (OR2) was $97.16 \pm 3.73$ and $60.34 \pm 2.51$, respectively. The surface carried negative charge with zeta potential of optimized batch was found to be $-18.40 \mathrm{mV}$.

\section{Surface morphology by TEM}

TEM results show that the selected optimized formulation (OR2) SLNs are circular in shape and particles are nanometric having size less than $125 \mathrm{~nm}$. The SLNs are smooth and perfectly separated on the surface. TEM image also confirms that SLNs have no drug crystal, i.e., irregular crystallization or rod crystal was visible (Fig. 2).

\section{XRD analysis}

The XRD pattern of pure drug showed various distinctive peaks in the region of $8-25^{\circ}(2 \theta)(6.24,9.26,10.88,15.57,16.51,17.10,18.75$, $19.54,22.75$, and 23.38 ) which indicated the highly crystalline nature of rosuvastatin. In case of lipid, the predominant peaks were observed at $19.08^{\circ}$ and $23.21^{\circ}$ that indicated the crystalline nature of lipid. The summation of distinctive diffraction peaks of rosuvastatin and lipid in the PM as shown in Fig. 3. Optimized formulation (OR2) exhibited considerable diminution of diffraction peaks than PM. Crystallinity index was found to be $72.35 \%, 58 \%, 64 \%$, and $52.03 \%$ for pure drug, lipid, PM, and optimized formulation (OR2) SLNs. This indicates that the drug was completely converted from crystalline to amorphous form. Hence, increased dissolution of the drug was observed since an amorphous form will dissolve at the faster rate owing to its higher internal energy and thermodynamic properties relative to crystalline materials.

DSC

DSC is productive technique for evaluating the thermal properties of formulation, giving data about the physiochemical condition of drug in the system [35]. The DSC thermogram shows that a sharp endothermic peak corresponding to the melting point of crystalline pure drug was found at $128^{\circ} \mathrm{C}$ and DSC thermogram of the stearic acid showed endothermic peak at $69^{\circ} \mathrm{C}$. The thermogram of the PM was merely a combination of thermogram of pure drug and lipid as shown in Fig. 4.

Table 2: Solubility study of drug in various lipids

\begin{tabular}{llll}
\hline S. No. & Lipid name & $\begin{array}{l}\text { Melting point } \\
\text { of lipid in }\left({ }^{\circ} \mathbf{C}\right)\end{array}$ & $\begin{array}{l}\text { Amount of lipid } \\
\text { required* }\end{array}$ \\
\hline 1. & Stearic acid & 69 & $48.66 \pm 0.87$ \\
2. & Compritol ATO 888 & 70 & $51.21 \pm 0.56$ \\
3. & Precirol ATO 5 & 56 & $53.34 \pm 0.86$ \\
4. & Glyceryl monostearate & 59 & $84.87 \pm 0.78$ \\
5. & Palmitic acid & 63 & $127.46 \pm 0.42$ \\
\hline
\end{tabular}

*All the values are expressed as mean $\pm S D, n=3$. SD: Standard deviation

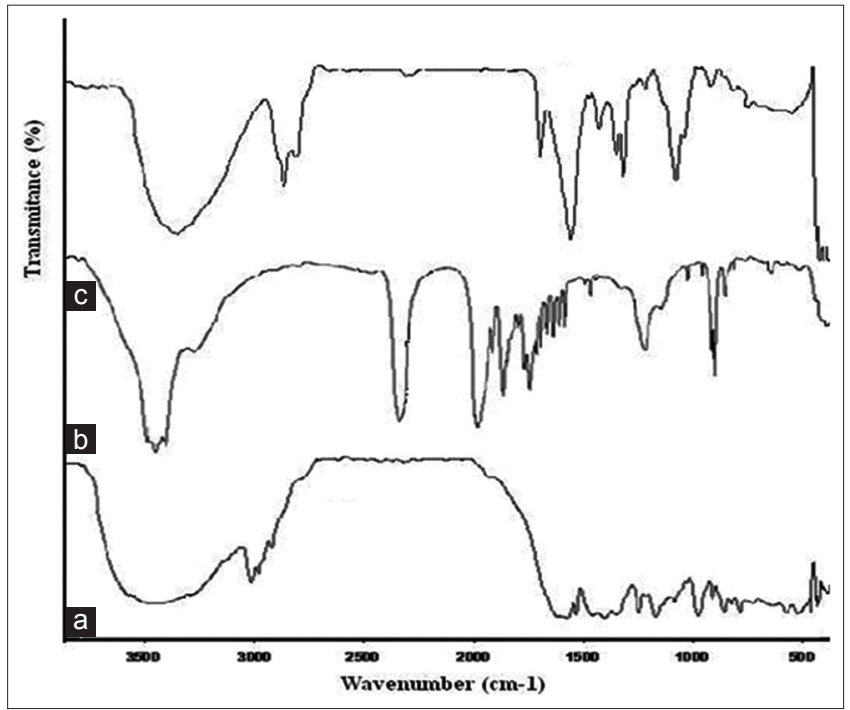

Fig. 1: Fourier transform-infrared spectra of (a) rosuvastatin calcium, (b) stearic acid, and (c) physical mixture

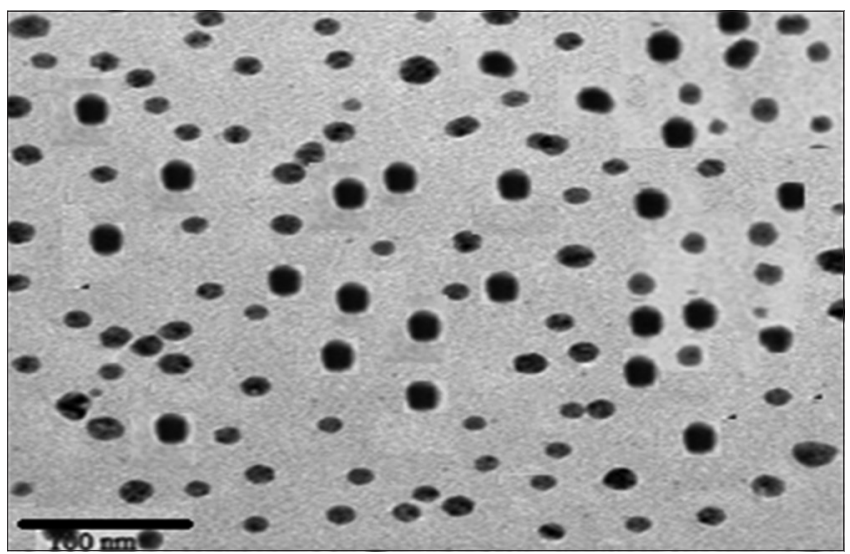

Fig. 2: Transmission electron microscopy image of rosuvastatin calcium-loaded optimized formulation (OR2) solid lipid nanoparticles 
Table 3: Observed response of different selected batches

\begin{tabular}{|c|c|c|c|c|c|}
\hline \multirow[t]{2}{*}{ Formulation code } & \multicolumn{5}{|l|}{ Response } \\
\hline & Entrapment efficiency* & Drug loading* & Particle size* (nm) & PDI & Zeta potential \\
\hline OR1 & $96.14 \pm 7.67$ & $58.71 \pm 5.65$ & $130.34 \pm 17.32$ & 0.403 & -12.47 \\
\hline OR3 & $95.25 \pm 5.65$ & $57.53 \pm 2.56$ & $141.65 \pm 3.89$ & 0.434 & -16.14 \\
\hline OR4 & $96.77 \pm 3.67$ & $59.47 \pm 1.78$ & $124.12 \pm 4.67$ & 0.442 & -12.47 \\
\hline
\end{tabular}

*All the values are expressed as mean \pm SD, $n=3$. SD: Standard deviation, PDI: Polydispersity index

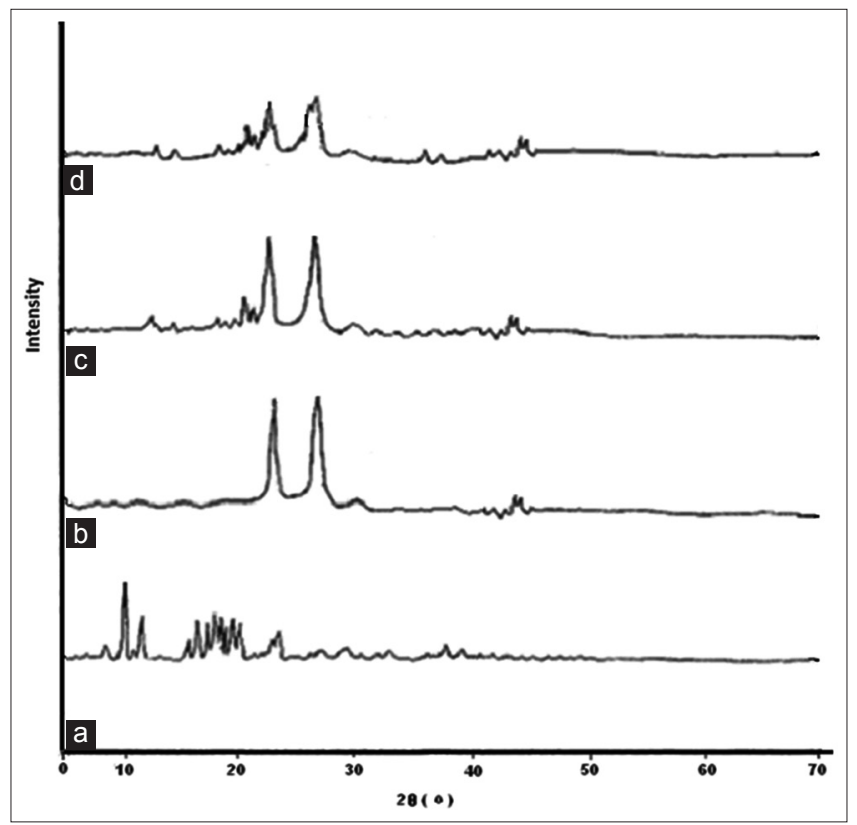

Fig. 3: X-ray diffraction spectra of (a) rosuvastatin calcium, (b) lipid (stearic acid), (c) physical mixture, and (d) optimized formulation (OR2) solid lipid nanoparticles

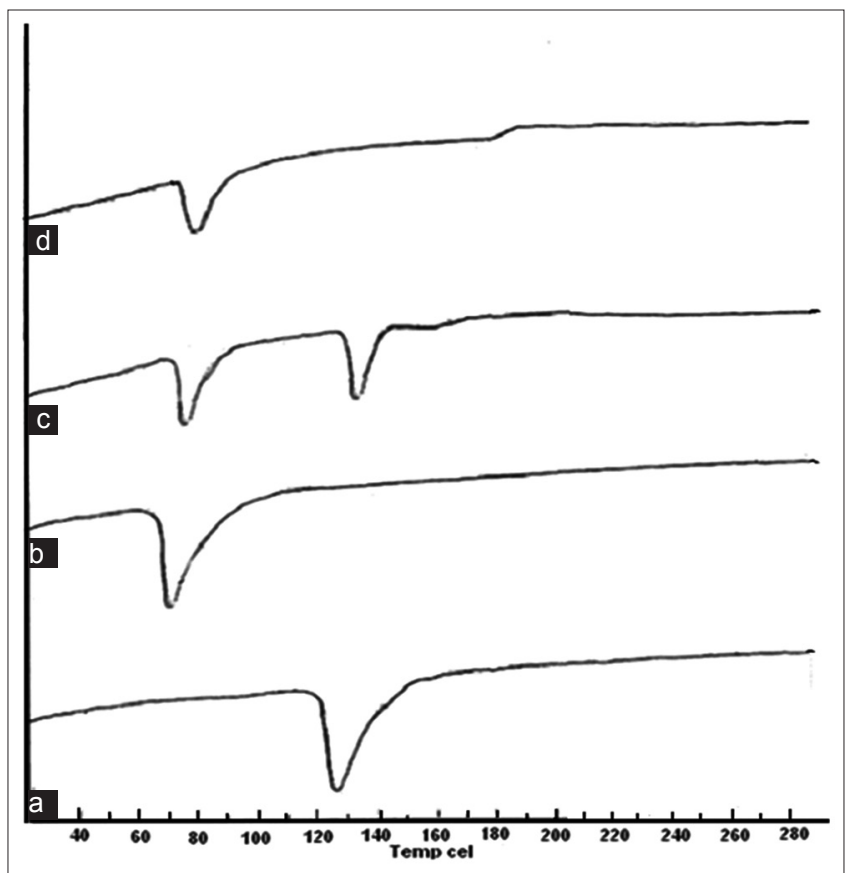

Fig. 4: Differential scanning calorimetry thermograms of

(a) rosuvastatin calcium, (b) lipid (stearic acid), (c) physical mixture, and (d) optimized formulation (OR2) solid lipid nanoparticles

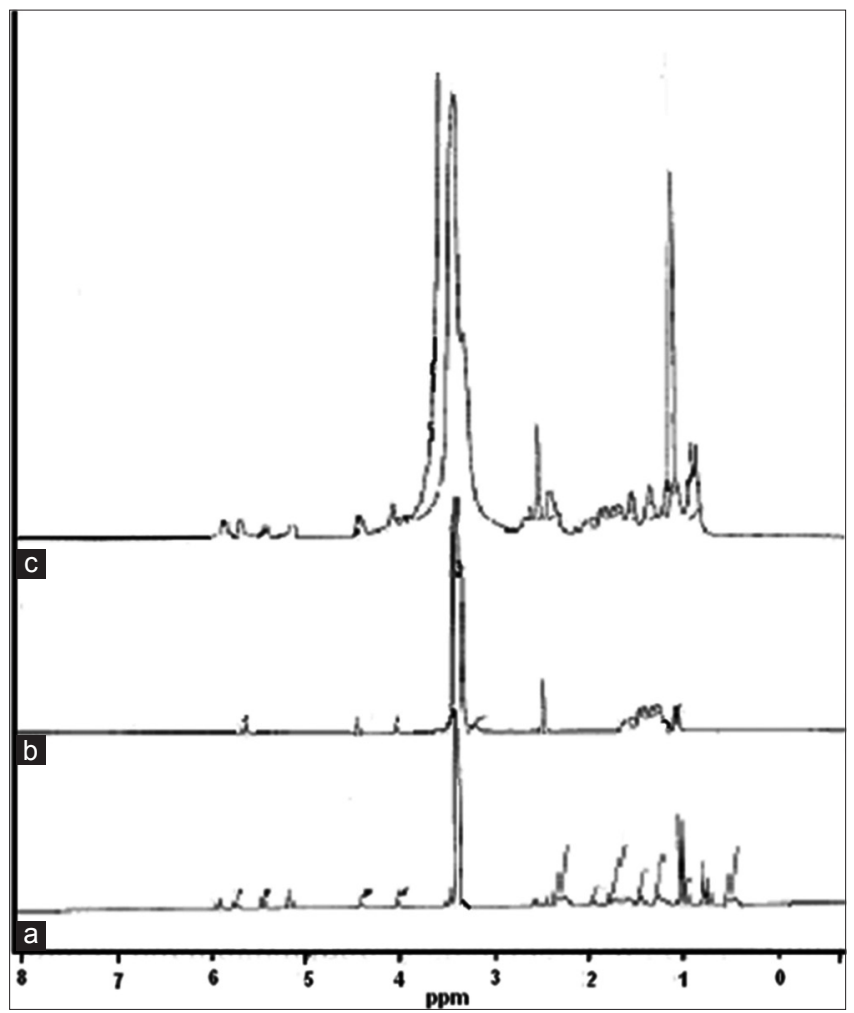

Fig. 5: ${ }^{1} \mathrm{H}$ nuclear magnetic resonance spectra of (a) rosuvastatin calcium, (b) lipid (stearic acid), and (c) optimized formulation (OR2) solid lipid nanoparticles

In the DSC thermogram of SLNs of optimized formulation OR2, the endothermic peak corresponding to melting of pure dug was absent. This might be due to the presence of the amorphous form of pure drug in the SLNs, and also, due to complete drug entrapment in the lipid matrix [36].

\section{${ }^{1}$ HNMR spectroscopy}

FT-NMR ( $\left.{ }^{1} \mathrm{HNMR}\right)$ spectrum of rosuvastatin, lipid (stearic acid), and SLNs of optimized formulation OR2 was shown in Fig. 5. The ${ }^{1} \mathrm{HNMR}$ spectrum of pure drug showed chemical shift from 5.927 to $5.958 \mathrm{ppm}$ $\left(\mathrm{d}, 1 \mathrm{H}, \mathrm{C}_{5} \mathrm{H}\right), 5.729$ to $5.791 \mathrm{ppm}\left(\mathrm{t}, 1 \mathrm{H}, \mathrm{C}_{4} \mathrm{H}\right), 5.478 \mathrm{ppm}\left(\mathrm{s}, 1 \mathrm{H}, \mathrm{C}_{6} \mathrm{H}\right)$, 2.248 to $2.376 \mathrm{ppm}(\mathrm{m}, 1 \mathrm{H}, \mathrm{OH}), 3.464 \mathrm{ppm}\left(\mathrm{s}, 10 \mathrm{H}, \mathrm{C}_{3} \mathrm{H}, \mathrm{C}_{7}, \mathrm{C}_{2}, \mathrm{C}_{3}, \mathrm{C}_{3^{\prime \prime}} \mathrm{C}_{8}\right.$, $\left.\mathrm{C}_{9}, \mathrm{C}_{10}, \mathrm{C}_{2^{\prime \prime}}\left[\mathrm{CH}_{3}\right]_{2}\right), 1.475$ to $1.81 \mathrm{ppm}\left(\mathrm{m}, 6 \mathrm{H}, \mathrm{C}_{3^{\prime \prime}}, \mathrm{C}_{7^{\prime \prime}}\right), 0.981$ to $1.031 \mathrm{ppm}$ $\left(\mathrm{m}, 6 \mathrm{H}, \mathrm{C}_{4^{\prime \prime}}, \mathrm{C}_{5^{\prime}}, \mathrm{C}_{4^{\prime}}\right.$ ), 1.423 to $1.470 \mathrm{ppm}\left(\mathrm{m}, 2 \mathrm{H}, \mathrm{C}_{5^{\prime}}\right.$ ), 3.304 to $3.710 \mathrm{ppm}$ $\left(\mathrm{m}, 9 \mathrm{H}, \mathrm{CH}_{3}\right)$, and $2.494 \mathrm{ppm}(\mathrm{s}, 1 \mathrm{H}, \mathrm{OH})$. Lipid showed chemical shift from 3.521 to $3.620 \mathrm{ppm}\left(\mathrm{m}, 89 \mathrm{H}, \mathrm{CH}_{2}\right), 1.011 \mathrm{ppm}\left(\mathrm{s}, 4 \mathrm{H}, \mathrm{CH}_{3}\right.$ ), and 3.294 to $3.428 \mathrm{ppm}(\mathrm{s}, 2 \mathrm{H}, \mathrm{CH})$ confirmed all protons of rosuvastatin calcium and stearic acid, thus identity and purity of sample. FT-NMR $\left({ }^{1} \mathrm{HNMR}\right)$ spectrum of optimized formulation OR2 showed similar peaks of drug and lipid, $5.928 \mathrm{ppm}\left(\mathrm{d}, 1 \mathrm{H}, \mathrm{C}_{5} \mathrm{H}\right), 5.590-5.759 \mathrm{ppm}(\mathrm{t}$, $\left.1 \mathrm{H}, \mathrm{C}_{4} \mathrm{H}\right), 5.434 \mathrm{ppm}\left(\mathrm{s}, 1 \mathrm{H}, \mathrm{C}_{6} \mathrm{H}\right), 2.321-2.364 \mathrm{ppm}(\mathrm{m}, 1 \mathrm{H}, \mathrm{OH}), 3.459-$ 3.718 ppm (m, 89H, $\left.\mathrm{CH}_{2}\right), 3.445$ ppm (s, $10 \mathrm{H}, \mathrm{C}_{3} \mathrm{H}, \mathrm{C}_{7}, \mathrm{C}_{2}, \mathrm{C}_{3}, \mathrm{C}_{3^{\prime \prime}} \mathrm{C}_{8}, \mathrm{C}_{9}, \mathrm{C}_{10}$, $\left.\mathrm{C}_{2^{\prime \prime}},\left[\mathrm{CH}_{3}\right]_{2}\right), 1.521-1.825$ ppm $\left(\mathrm{m}, 6 \mathrm{H}, \mathrm{C}_{3^{\prime \prime}}, \mathrm{C}_{7^{\prime \prime}}\right), 0.970-1.024 \mathrm{ppm}(\mathrm{m}, 6 \mathrm{H}$, 
$\left.\mathrm{C}_{4^{\prime \prime}} \mathrm{C}_{\mathrm{F}^{\prime}}, \mathrm{C}_{4}\right), 1.026 \mathrm{ppm}\left(\mathrm{s}, 4 \mathrm{H}, \mathrm{CH}_{3}\right), 1.454-1.479 \mathrm{ppm}\left(\mathrm{m}, 2 \mathrm{H}, \mathrm{C}_{5^{\prime}}\right), 3.312-$ $3.582 \mathrm{ppm}\left(\mathrm{m}, 9 \mathrm{H}, \mathrm{CH}_{3}\right)$, and $3.325 \mathrm{ppm}(\mathrm{s}, 2 \mathrm{H}, \mathrm{CH})$ which confirms the intermolecular hydrogen bonding between drug and lipid [27]

\section{In vitro drug release and release kinetics study}

The optimized rosuvastatin calcium-loaded SLNs (OR2) showed much faster in vitro dissolution rate than pure drug suspension as shown in Fig. 6. The optimized SLNs show drug release from $21.70 \pm 3.23 \%$ to $88.70 \pm 3.59 \%$. It was apparent that optimized formulation showed a rapid initial release followed by slow drug release. The rapid release of drug at initial phase may be due to release of drug takes place from the surface of nanoparticles, while at the later stage sustained release of drug was observed from nanoparticles core as a consequence of lipid hydration and swelling that is responsible for the prolonged release, which is desired for controlled release [37]. The drug release data were fitted into zero-order, first-order, and Higuchi's model [9]. For the optimized batch, the highest value of correlation coefficient $\left(\mathrm{R}^{2}=0.9905\right)$ was observed for Higuchi' model, followed by the Korsmeyer-Peppas $\left(R^{2}=0.9754\right)$, first-order $\left(\mathrm{R}^{2}=0.9612\right)$, and zero-order $\left(\mathrm{R}^{2}=0.9291\right)$ models, as shown in Fig. 6 .

\section{Pharmacokinetics studies}

The different pharmacokinetic parameters of optimized rosuvastatinloaded SLNs (OR2) when administered through oral route were determined, and concentrations of drug in blood plasma were calculated as shown in Table 4. Results of the study showed that optimized rosuvastatin-loaded SLNs (OR2) remarkably increased the rosuvastatin concentration in plasma as compared to concentration found with plain drug suspension after oral administration. The two-tailed unpaired $t$-test showed statistically significant differences in the drug plasma concentration $(\mathrm{p}<0.05)$ between the optimized rosuvastatin-loaded SLNs (OR2) and plain drug suspension after oral administration at $\mathrm{T}_{\max }$. The optimized loaded SLNs (OR2) exhibited 4.44-fold increase in bioavailability as compared to plain drug suspension as shown in Fig. 7 and able to provide sustained release for prolong period of time. The rate and extent of absorption of drug form SLNs suggested excellence in the oral bioavailability of drug from the system.

\section{Stability studies}

As per the ICH guidelines, for optimized formulation ROS-SLNs (OR2) as intended to be stored at $4 \pm 2^{\circ} \mathrm{C}$ (refrigerator), $25 \pm 2^{\circ} \mathrm{C} / 60 \pm 5^{\circ} \mathrm{C}$ $\mathrm{RH}$, and $40 \pm 2^{\circ} \mathrm{C} / 75 \pm 5^{\circ} \mathrm{C}$ RH and samples withdrawn at $0,1,3$, and 6 months. There were no significant changes observed in particle size and PDI when they are stored at $4 \pm 2^{\circ} \mathrm{C}$ (refrigerator), $25 \pm 2{ }^{\circ} \mathrm{C} / 60 \pm 5^{\circ} \mathrm{C}$ $\mathrm{RH}$, but particle size was increased due to zeta potential dropped at $40 \pm 2^{\circ} \mathrm{C} / 75 \pm 5^{\circ} \mathrm{C} \mathrm{RH}$. This type of effect might be due to dissolution of
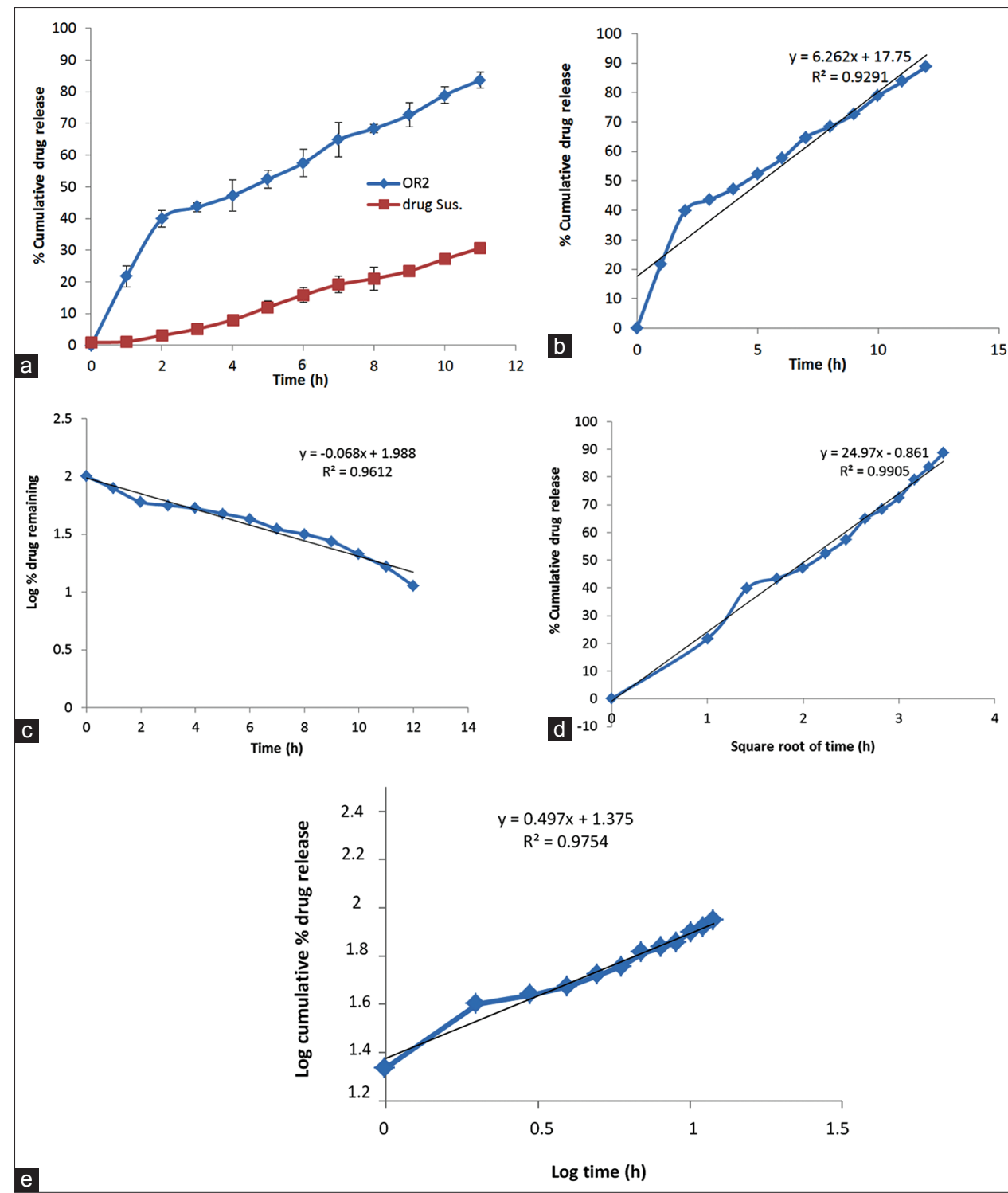

Fig. 6: In vitro drug release from (a) optimized formulation (OR2) solid lipid nanoparticles, (b) zero-order release model, (c) first-order release model, (d) Higuchi release model, and Korsmeyer peppers release model 
the coating of lipid at accelerated temperature and humidity which leads to cluster or aggregation of particles ( $p<0.05$, Table 5) [24].

\section{CONCLUSION}

In the present study, rosuvastatin-loaded SLNs were successfully prepared by the slightly modified emulsification-diffusion technique and evaluated for different parameters such as particle size, PDI, zeta potential, in vitro release, pharmacokinetic, and stability studies. The mean particle size of SLNs decreased with increase in surfactant concentration. All the measurements were found to be in acceptable range. In vitro drug release was found to be $88.70 \pm 3.59 \%$ over $12 \mathrm{~h}$ showing initial rapid and then sustained drug release. Pharmacokinetic studies were performed on male Wistar rats, and it was found that optimized SLNs were able to improve bioavailability with 4-fold as compared to plain drug suspension and able to provide sustained release for prolong period of time.

\section{ACKNOWLEDGMENTS}

The authors express their gratitude to Sun Pharmaceuticals Ltd., Gurgaon, Haryana, India, for providing gift sample rosuvastatin

Table 4: Plasma pharmacokinetic parameters after oral administration of plain drug suspension and optimized formulation (OR2) SLNs

\begin{tabular}{llll}
\hline S. No. & Pharmacokinetic parameters & Plain drug suspension & Optimized ROS SLNs (OR2) \\
\hline 1. & $\mathrm{C}_{\max }(\mu \mathrm{g} / \mathrm{mL})$ & $48.62 \pm 4.63$ & $72.74 \pm 7.63$ \\
2. & $\mathrm{~T}_{\max }(\mathrm{h})$ & 2 & 4 \\
3. & $\mathrm{AUC}_{0-\mathrm{t}}(\mu \mathrm{g} \cdot \mathrm{h} / \mathrm{mL})$ & $439.81 \pm 43.72$ & $958.585 \pm 77.7356$ \\
4. & $\mathrm{~K}_{\mathrm{E}}\left(\mathrm{h}^{-1}\right)$ & $0.034478 \pm 0.00652$ & $0.039576 \pm 0.0083$ \\
5. & $\mathrm{~T}_{1 / 2}(\mathrm{~h})$ & $7.735 \pm 0.942$ & $12.73 \pm 1.02$ \\
6. & $\mathrm{MRT}$ & $11.08765 \pm 1.5234$ & $6.7995 \pm 0.7423$ \\
7. & $\mathrm{AUMC}$ & $4876.46 \pm 273.74$ & $6517.899 \pm 392.7456$ \\
\hline
\end{tabular}

*All the values are expressed as n=6, mean \pm SD. SD: Standard deviation, SLNs: Solid lipid nanoparticles, ROS: Rosuvastatin calcium

Table 5: Characteristics of optimized SLNs after 6 month stability studies at different conditions

\begin{tabular}{|c|c|c|c|c|c|c|}
\hline \multirow[t]{2}{*}{$\operatorname{Temp}\left({ }^{\circ} \mathrm{C}\right) / \mathrm{RH}(\%)$} & \multirow[t]{2}{*}{ Time (month) } & \multicolumn{5}{|c|}{ Characteristics parameter } \\
\hline & & $\begin{array}{l}\text { Particle } \\
\text { size (nm) }\end{array}$ & PDI & $\begin{array}{l}\text { Zeta } \\
\text { potential }(\mathrm{mV})\end{array}$ & $\begin{array}{l}\text { Entrapment } \\
\text { efficiency }(\%)\end{array}$ & Drug loading (\%) \\
\hline \multirow{4}{*}{$4 \pm 2^{\circ} \mathrm{C}$ (refrigerator) } & 0 & $112.56 \pm 3.35$ & 0.453 & $-18.5 \pm 1.3$ & $95.12 \pm 2.32$ & $59.54 \pm 1.54$ \\
\hline & 1 & $116.74 \pm 2.43$ & 0.432 & $-17.5 \pm 1.5$ & $93.89 \pm 3.20$ & $60.25 \pm 2.34$ \\
\hline & 3 & $115.32 \pm 2.76$ & 0.342 & $-17.4 \pm 1.7$ & $96.93 \pm 2.87$ & $60.37 \pm 2.45$ \\
\hline & 6 & $124.65 \pm 3.23$ & 0.478 & $-18.2 \pm 1.9$ & $97.65 \pm 1.76$ & $58.89 \pm 1.96$ \\
\hline \multirow[t]{4}{*}{$25 \pm 2^{\circ} \mathrm{C} / 60 \pm 5^{\circ} \mathrm{C} \mathrm{RH}$} & 0 & $112.56 \pm 3.35$ & 0.453 & $-18.5 \pm 1.3$ & $95.12 \pm 1.36$ & $59.54 \pm 1.21$ \\
\hline & 1 & $112.74 \pm 1.04$ & 0.552 & $-17.3 \pm 1.2$ & $92.53 \pm 2.27$ & $60.15 \pm 2.75$ \\
\hline & 3 & $119.72 \pm 4.76$ & 0.459 & $-16.2 \pm 1.2$ & $94.93 \pm 2.34$ & $58.37 \pm 1.46$ \\
\hline & 6 & $128.43 \pm 5.46$ & 0.598 & $-15.9 \pm 3.2$ & $95.65 \pm 2.14$ & $59.64 \pm 2.58$ \\
\hline \multirow{4}{*}{$40 \pm 2^{\circ} \mathrm{C} / 75 \pm 5^{\circ} \mathrm{C} \mathrm{RH}$} & 0 & $112.56 \pm 3.35$ & 0.453 & $-18.5 \pm 1.3$ & $95.12 \pm 2.32$ & $59.54 \pm 1.23$ \\
\hline & 1 & $121.74 \pm 2.43$ & 0.432 & $-14.5 \pm 1.8$ & $93.89 \pm 2.57$ & $60.63 \pm 2.87$ \\
\hline & 3 & $315.32 \pm 2.76$ & 0.542 & $-12.4 \pm 2.8$ & $94.85 \pm 1.58$ & $57.37 \pm 1.36$ \\
\hline & 6 & $1124.65 \pm 3.23$ & 0.678 & $-7.54 \pm 3.5$ & $91.37 \pm 2.52$ & $54.89 \pm 0.96$ \\
\hline
\end{tabular}

*All the values are expressed as $n=3$, mean \pm SD; $P<0.05$. SD: Standard deviation

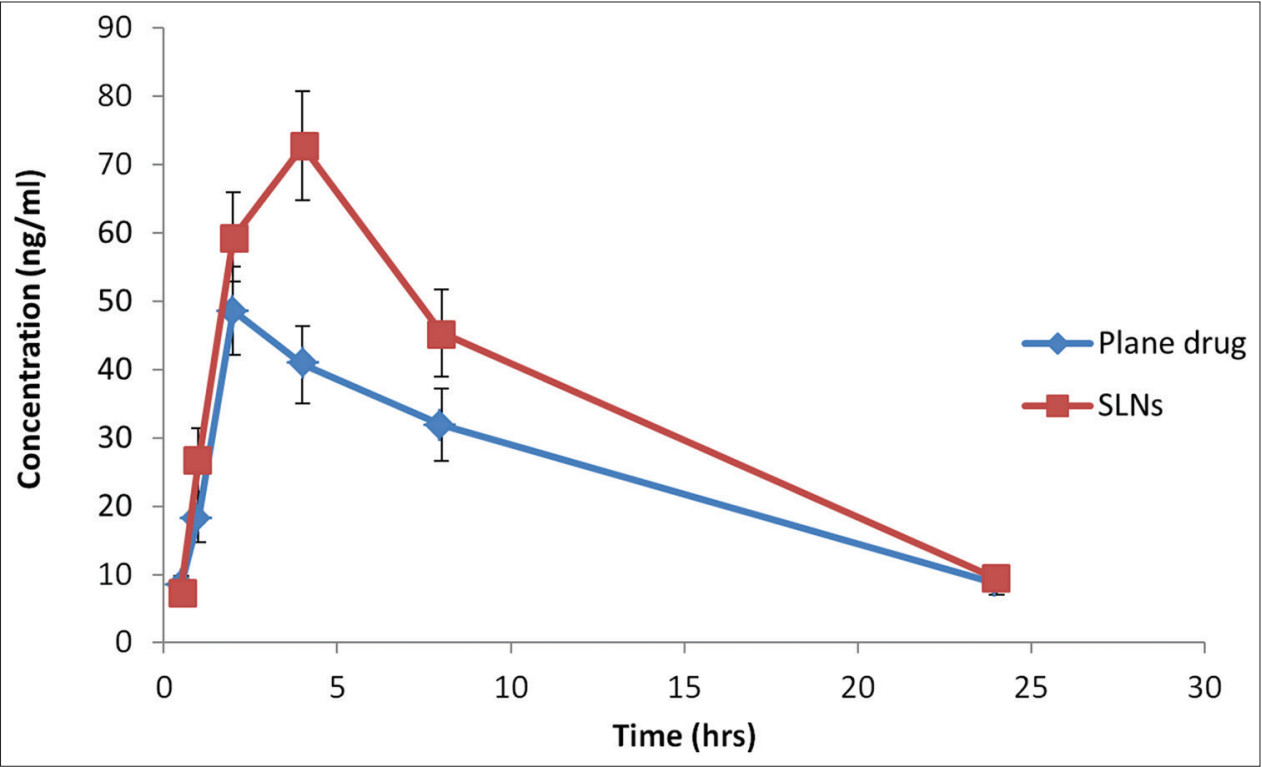

Fig. 7: Plasma concentration versus time profile of rosuvastatin after single-dose oral administration of plain drug suspension and optimized formulation (OR2) solid lipid nanoparticles 
calcium. The authors are thankful to the management of the Department of Pharmacy, Bhagwant University, Ajmer, Rajasthan, India, for providing the facilities to carry out the research work. The authors are also thankful to the Principal Prof. (Dr.) D.K. Sharma and management of Devsthali Vidyapeeth College of Pharmacy, Kichha Road, Lalpur, Rudrapur, U.S. Nagar, UK, India, for providing facilities for animal study.

\section{AUTHOR'S CONTRIBUTION}

The first author has carried out all the research work. The second and third authors have provided project concept, work design, manuscript preparation, and critical revision.

\section{CONFLICTS OF INTEREST}

The authors declared that they have no conflicts of interest.

\section{REFERENCES}

1. Kanwade V, Mahale NB, Salunkhe KS, Shinde PP, Chaudhari SR. Recent trends on immediate release dosage form: A review. World J Pharm Res 2014;3:271-97.

2. Ahuja N, Katare OP, Singh B. Studies on dissolution enhancement and mathematical modeling of drug release of a poorly water-soluble drug using water-soluble carriers. Eur J Pharm Biopharm 2007;65:26-38.

3. Kamboj S, Bala S Nair AB. Solid lipid nanoparticles: An effective lipid based technology for poorly water soluble drugs. Int J Pharm Sci Rev Res 2010;5:78-89.

4. Gopi G, Kannan K. Formulation development and optimization of nateglinide-loaded ethyl cellulose nanoparticles of box behnken design. Int J Pharm Pharm Sci 2015;7:310-15.

5. Yadav N, Khatak, S, Sara UV. Solid lipid nanoparticles-a review. Int J App Pharm 2013;5:8-18.

6. Waghmare AS, Grampurohit ND, Gadhave MV, Gaikwad DD, Jadhav SL. Solid lipid nanoparticles: Apromising drug delivery system. Int Res J Pharm 2012:3:100-7

7. Ahmad M, Usman M, Sohail M. Pharmacokinetic interactions of Rosuvastatin: A review. J Pharm Alter Med 2012:1-7.

8. Luvai A, Mbagaya W, Hall AS, Barth JH. Rosuvastatin: A review of the pharmacology and clinical effectiveness in cardiovascular disease. Clin Med Insights Cardiol 2012;6:17-33.

9. Shah KA, Date AA, Joshi MD, Patravale VB. Solid lipid nanoparticles (SLN) of tretinoin: Potential in topical delivery. Int $\mathrm{J}$ Pharm 2007:345:163-71.

10. Silpa NR, Chhakravarti N, Yerram C, Hemanth PK. Moxifloxacin loaded solid lipid nanoparticles (SLNs): Preparation and characterization. Asian J Pham Res 2012:2:105-12.

11. Singh H, Gupta RD, Gautam G. Preparation and optimization of rosuvastatin calcium loaded solid lipid nanoparticles by central composite design. World J Pharm Res 2017;6:1055-71.

12. Yasir M, Sara UV. Preparation and optimization of haloperidol loaded solid lipid nanoparticles by box-Benken design. J Pharm Res 2013;7:551-8

13. Singh AP, Saraf SK, Saraf SA. SLN approach for nose-to-brain delivery of alprazolam. Drug Deliv Transl Res 2012;2:498-507.

14. Serralheiro A, Alves G, Fortuna A, Falcão A. Intranasal administration of carbamazepine to mice: A direct delivery pathway for brain targeting. Eur J Pharm Sci 2014;60:32-9.

15. Trotta M, Debernardi F, Caputo O. Preparation of solid lipid nanoparticles by a solvent emulsification-diffusion technique. Int $\mathrm{J}$ Pharm 2003; $257: 153-60$

16. Abdul HS, Nisha N. Development of solid lipid nanoparticles of rosuvastatin calcium. BioMedRx 2013;1:536-48.

17. Liu D, Jiang S, Shen H. Diclofenac sodium loaded solid lipid nanoparticles prepared by emulsion solvent diffusion method. J Nano Res 2011; 13(6):2375-86.

18. Shailesh SC, Veena SB, Vivek RT, Sanjay JS, Mrunal UP. Formulation and evalua-tion of nimodipine-loaded solid lipid nanoparticles deliv-ered via lymphatic transport system. Coll Sur B Bioint S 2012;97:109-16

19. Priyanka K, Abdul HS. Preparation and evaluation of montelukest sodium loaded solid lipid nanoparticles. J Y Pharm 2012;2012:129-37.

20. Korsmeyer RW, Gurny R, Doelker E, Buri P, Peppas NA. Mechanisms of solute release from porous hydrophilic polymers. Int J Pharm 1983;15:25-35.

21. Higuchi T. Mechanism of sustained-action medication. Theoretical analysis of rate of release of solid drugs dispersed in solid matrices. J Pharm Sci 1963;52:1145-9.

22. Ritger PL, Peppas NA. A simple equation for description of solute release II Fickian and anomalous release from swellable devices. J Control Rel 1987;5:37-42.

23. Suvakanta D, Padala NM, Lilakanta N, Prashant C. Kinetic modelling on drug release from controlled drug delivery systems. Acta Poloniac Pharm 2010;67:217-23.

24. Yasir M, Sara UV. Solid lipid nanoparticles for nose to brain delivery of haloperidol: In vitro drug release and pharmacokinetics evaluation. Acta Pharm Sin B 2014;4:454-63.

25. Goddeeris C, Mooter GD. Free flowing solid dispersions of anti-HIV drug UC-781 with poloxamer 407 and a maximum amount of TPGS 1000: Investigating the relationship between physiochemical characteristics and dissolution behaviour. Eur J Pharm Sci 2008;35:104-13

26. Panakanti PK, Panakanti G, Reddy S, Somagoni J, Yamasai MR. Atorvastatin loaded solid lipid nanoparticles: Formulation, optimization and in vitro characterization. IOSR J Pham 2012;2:23-32.

27. Spulber M, Pintela M, Fifere A. Inclusion complexes of 5-flucytosine with $\beta-C D$ and HP $\beta-C D$ : Characterization in aqueous solution and in solid state. J Incl Phenom Macrocycl Chem 2007;2007:1-10.

28. Suares D, Prabhakar B. Oral delivery of rosuvastatin lipid nanocarriers: Investigation of in vitro and in vivo profile. Int J Pharm Sci Res 2016;7:4856-64.

29. Gadad AP, Swetha GT, Panchaxari MD, Vinayak SM, Uday BB. Rosuvastatin loaded nanostructured lipid carrier: For enhancement of oral bioavilability. Ind J Pharm Educ Res 2016;50:605-11.

30. Gaur PK, Mishra S, Bajpai M, Mishra A. Enhanced oral bioavailability of effavirenz by solid lipid nanoparticles: In vitro drug release and pharmacokinetics studies. Biomed Res Int 2014;2014:1-9.

31. Muller RH, Mader K, Gohla S. Solid lipid nanoparticles (SLN) for controlled drug delivery - a review of the state of the art. Eur J Pharm Biopharm 2000;50:161-77.

32. Agarwal R, Malthar HP, Madhumathi CH, Reddy BC. Development and pharmacodynamic evaluation of rosuvastatin loaded nanostructured lipid carriers for oral administration. World J Phar Pharm Sci 2015;4:699-16.

33. Papadimitriou S, Papageorgiou GZ, Kanaze Fl. Nanoencapsulation of nimodipine in novel biocompatible poly (propylene-co-butylene succinate) aliphatic copolyesters for sustained release. J Nanomater 2009;2009:1-11.

34. Sanjula B, Shah FM, Javed A, Alka A. Effect of poloxamer 188 on lymphatic uptake of carvedilol-loaded solid lipid nanoparticles for bioavailability enhancement. J Drug Target 2009;17:249-56.

35. Ruby JJ, Pandey VP. Chitosan nanoparticles as a nasal drug delivery of memantine hcl. Int J Pharm Pharm Sci 2015;7:34-7.

36. Chen J, Qiu L, Hu M, Jin Y, Han J. Preparation, characterization and in vitro evaluation of solid dispersions containing docetaxel. Drug Dev Ind Pharm 2008:34:588-94.

37. Sadeghi A, Dorkoosh FA, Avadi MR. Preparation, characterization and antibacterial activities of chitosan, TMC and DEMC nanoparticles loaded with insulin using both ionotropic gelation and polyelectrolyte complexation methods. Int J Pharm 2008;355:299-6. 